\title{
Optimization of delivery adherence based on capacity planning and bid pricing
}

\author{
B. Denkena ${ }^{1} \cdot$ M.-A. Dittrich ${ }^{1} \cdot$ S. Wilmsmeier ${ }^{1} \cdot$ S. Stamm ${ }^{1}$
}

Received: 17 December 2019 / Accepted: 23 March 2020 / Published online: 5 April 2020

(c) The Author(s) 2020

\begin{abstract}
Sales revenues of enterprises are often subject to seasonal fluctuation. This leads to high or low utilized resources and this in turn to revenue losses. Hence, the enterprises invest a high effort to improve long and short-term resource utilization. In this context, disregarding future capacity utilization within the process of quotation leads to short-timed capacity adjustments for instance, additional work hours across seasons. This paper presents an approach which focuses on dependencies between costs and capacity by linking cost pricing and production scheduling. A first evaluation at an MTO supplier shows that order delays can be reduced by up to $95 \%$ and total costs by $21 \%$ compared to using the most appropriate priority rule.
\end{abstract}

Keywords Scheduling $\cdot$ Production planning $\cdot$ Cost $\cdot$ Economics $\cdot$ Decision making

\section{Introduction}

Machining production is characterized by the workshop principle. Thus, it is required to handle individual products, small lot sizes and different resulting processing sequences of goods and services. Typical enterprises are make-to-order (MTO) manufacturers which are often small and medium sized enterprises (SME). These are often subject to seasonally fluctuating sales revenues, which is why a high degree of operational flexibility is required when responding to shortterm peaks in capacity utilization. Building up sufficient capacity, e.g. employees, machinery, to complete orders on time is not always appropriate, as capacity utilization throughout the year does not justify the associated investments. Even approaches to adaptive production control, e.g. adaptive process planning and control by Denkena et al. [1], which increase flexibility and the ability to react to disturbances in an optimized way, are not suitable to compensate for these seasonal fluctuations in capacity.

In the machining industry, SME have high expectations regarding long-term and short-term production levelling due to demand fluctuation while maintaining an even production utilization and cost controlling. The costs for bid prices are

S. Stamm

stamm@ifw.uni-hannover.de

1 Institute of Production Engineering and Machine Tools, An der Universität 2, 30823 Garbsen, Germany calculated based on the cost of a standard shift. However, if the product is, for example, produced in the night shift, the previous cost calculation is no longer valid. Nonetheless, the additional costs occur as a result and they are not taken into account in prior cost calculating. Alternatively, penalty charges have to be paid for delayed deliveries [2, 3]. This leads to the necessity of a cost calculating system, which regards the utilization of resources. The combination of cost calculation and production planning makes it possible to price in necessary capacity increases, e.g. overtime, shifts, at short notice through an adjusted offer price or to persuade the customer to choose a later delivery date at lower costs.

Classical approaches for production planning and control (PPC) do not link the individual disciplines of production planning and sales. The approaches are mainly influenced by theoretical views on PPC in a closed loop control [2] to avoid capacity adjustment measures. These approaches are partly extended by capacity adjustment measures like additional work hours or shift expansion depending on their adjustment periods. Chehade acknowledged that the costs of these adjustment measures are of significant interest [4]. Therefore, this paper presents an approach which enables SME to link capacity utilization, cost calculation and bid pricing. For this purpose, the approach is firstly developed based on the current state of the art, then applied to a real data set and evaluated on a case study. 


\section{State of the art}

Linking costs and capacity is a recognized problem in several areas. However, it has not yet been not fully addressed. Slotnick provided a brief evaluation of order acceptance and scheduling in 13 different methodical views on this topic. The approaches were analyzed based on the number of considered machines, pre-emption, objective and pricing [3]. Only three of the papers took pricing into account in scheduling [5-7]. The other authors subsequently evaluate the planning based on the resulting production costs. Slotnick concluded that future work should address the interaction between disciplines such as order acceptance, pricing and capacity loading [3].

Charnsirisakskul [5] invented a simultaneous pricing regarding holding costs and tardiness penalties. The goal is to evaluate the capabilities of multi customer pricing instead of single customer pricing. Furthermore, it is pointed out that price flexibility leads to better results than lead time flexibility if there is no inventory flexibility for the manufacturer. Pourbabai $[6,7]$ regards a scheduling algorithm based on linear programming that supports the decision in order acceptance or rejection. The goal is to calculate the optimal size of production batches by splitting. Costs are taken into account by fixed order prices.

Carvalho et al. [8] compared approaches for capacity adjustment measures to minimize production costs or to maximize profit from the production point of view. They classified the approaches according to their empirical nature and concluded that most of the authors did not include real-world problems [8]. Real-world means that the authors did not develop and validate their approaches based on real data sets. Instead, they used simulationbased data that do not allow direct conclusions regarding practical applicability. In contrast, Alfieri et al. [9, 10] only concentrated on production planning and not on costs. The approach of Carvalho et al. [8] took into account the variable costs for processing and additional work hours, the capacity change costs, personnel costs and subcontracting to minimize the costs by using linear programming. Fixed costs were not included. Further, Ho took into account uncertain demand of products by implementing the density function of product demand into the cost price by using a nonlinear model optimization [11].

Other approaches in PPC consider capacity adjustments measures and costs at an early stage of the production process. Methods like workload control (WLC), order review and release (ORR) and bottleneck load-oriented release (BLOR) are main targets [12]. Kingsman, for example, referred to an "analytical model of dynamic capacity planning at the stage of customer inquiry" [13] by using flexible capacity of single workstations. In addition, Kingsman explained the planning problem of bidding and order acceptance. He also emphasized the importance of the delivery date and the price in this early stage of the production process. Nevertheless, only the delivery dates are considered in scheduling, because enterprises try to keep the price as low as possible [13]. Kingsman also developed an "overall decision support system for dealing with inquiries" [14]. It is divided into three modules: estimation module, capacity planning module and marketing module. The estimation of bid prices is mainly influenced by a database of past prices and won bids.

Other studies focus on investment strategies for capacity planning [15]. Some approaches already consider a costcapacity-ratio as activity-based costing and time-driven activity-based costing. These are basic models that use costs per capacity units (machine hour rate) and the completion time of tasks as the production time $[16,17]$.

Wouters developed a cost calculation system that meets the requirements of a particular SME. He also identified the difficulties in allocating labour costs to a specific product because multi-machine processing is often required. The author asserted that the determination of cost changes in real-time adjustments should be the focus of future work [17]. Ou considered adjustment costs in cost calculating. In the case of capacity adjustments, these costs occur if the capacity differs from the previous period [18]. This depends on the labour cost system and the machine hour rate calculation.

Besides PPC, revenue management (RM) also offers approaches for linking capacity and costs. The basic idea related to that is to break down a standardized product portfolio into partial capacity units, e.g. services like seats in airplanes. A major application requirement in RM is heterogeneous customer behavior [19]. The management process of cost and capacity is based on pricing mechanism, which increases the price while the current demand exceeds the expected demand. In contrast, the price decreases if the current demand underruns the expected demand [20]. Thus, the opportunity-related costs (OC) as a control principle of capacity within the framework of RM represents a central approach for decision support regarding the acceptance or rejection of an order [20]. The feasibility of linking costs and capacity based on RM approaches in the area of production is not generally given. Customer behavior, for example, shows different price sensitivities [21], which means that there is not always a willingness to pay higher prices for short-term order processing or lower prices for later delivery. In addition, the rejection of orders is not considered.

In conclusion, several approaches, which deal with issues of linking capacity and costs mainly in linear programming, are found in literature. However, these approaches only focus on separate topics, such as scheduling, order release or costs 
calculation, and do not match the insights of these topics. There is no superior approach, which takes into consideration real-world problems, e.g. acceptance of delays in contrast to rejection, and grown cost-structures of SME. If the costs are taken into consideration, they are calculated globally for the entire capacity utilization in production. For the existing models in RM, not all the applications prerequisites for an effective use in machining production are met. Nevertheless, there is the potential to transfer the basic idea of the RM, the price formation of capacity utilization, to MTO production. In particular, it has to be analyzed if the definition of OC within the framework of RM can be transferred to production as the production costs of short-term capacity adjustment measures are not considered in RM. However, the additional wage costs may be regarded as OC because they compensate losses. Nevertheless, the wage costs cannot be taken into account without considering cause-related costs for capacity adjustments. These additional costs vary depending on the orders causing them. To overcome this issue, approaches should focus more on addressing this relation. In real-world MTO, production forward scheduling is often used to maintain a high utilization. Contrary to this, a backward scheduling ensures a just-in-time production but causes gaps in schedules and hence economic losses. As a result, it is necessary to take into account additional wage costs during scheduling to derive minimal wage costs due to customer price sensitivity.

\section{Approach for dynamic bid pricing under consideration of adjustment costs}

The present approach includes five modules depicted in Fig. 1. The modules of customer classification, forecast and order process are described in detail in a previous publication [22]. Hence, in this paper only a short overview of these modules is given. The customers are first categorized into A, B and C classes (Classification model) by using pareto analysis on economic aspects. The goal is to ensure the confirmed date of delivery for prioritized "A" customer. Furthermore, a forecast of the future capacity utilization is calculated depending on these customer classes to check if the approximated time of production is within a highly utilized period. The forecast is based on an auto regressive moving average (ARIMA) algorithm taking due dates of past production orders into account. In underutilized periods, the orders are planned without capacity restrictions. Otherwise, the schedule model including the new offered order is used to determine the necessary capacity adjustment measures. Seasonal fluctuations are considered by activating or blocking the capacity cells depending on the required demand. The capacity cells are released according to the forecast. If a class contingent has already been reached, no further cells are released. By scheduling the orders, possible capacity

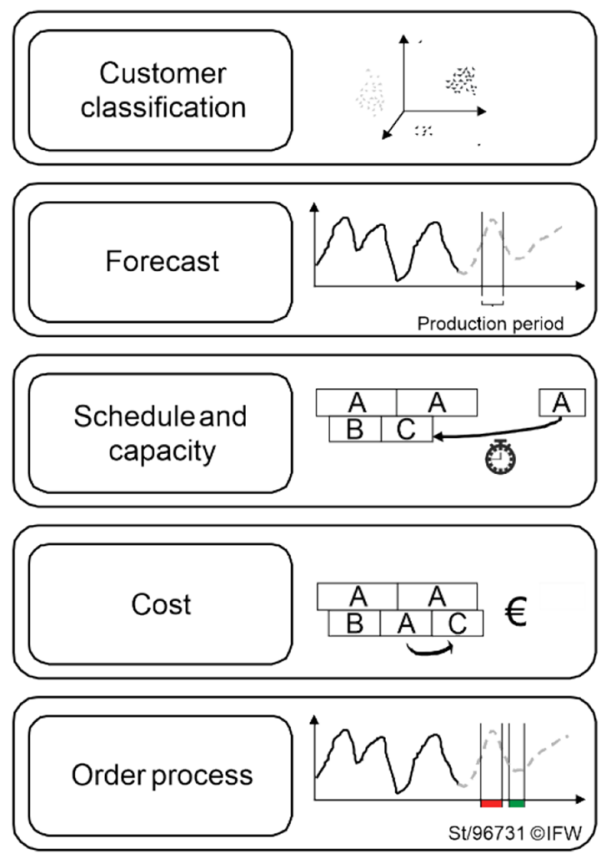

Fig. 1 Method of dynamic bid pricing

adjustments can be defined and the resulting costs will be added to the quote of the corresponding order according to the causation principle. These additional costs are calculated as additional wage costs caused by capacity adjustments during scheduling on the basis of the approach for dynamic bid pricing in Denkena et al. [22]. Furthermore, an assignment of fixed and variable costs per planning period must be guaranteed and implemented in a dynamic machine hour rate.

The forecast is used to determine a date of delivery in a period of low capacity utilization, which takes place in the order processing, to offer customers an alternative date of delivery. The background is the predicted capacity of the respective customer class. This is taken into account in the schedule and capacity model using dummy orders. When the orders are confirmed, the contingent (amount of dummy orders in hours) for the respective customer class is filled. If the contingent is reached, an alternative date of delivery is determined. This is intended to encourage customers to order in periods with low capacity utilization.

\subsection{Schedule model}

The interaction between the schedule and the cost model is illustrated in Fig. 2. Within the schedule model, the dates of delivery of all orders and whether they arrived in time or not are analyzed. The adjustment measures are systematically used to ensure that orders from A and B customers are always available on the delivery date. The achievement of minimal costs and securing of the delivery date is made possible by following three steps: 


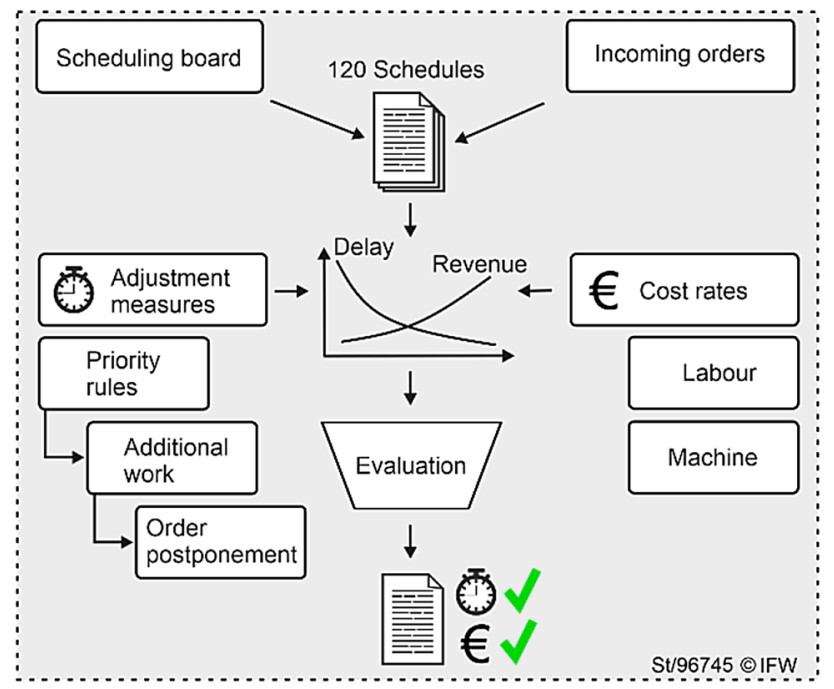

Fig. 2 Procedure of the dynamic bid pricing algorithm

(1) Scheduling according to time-based priority rules

(2) Optimization by using capacity adjustment measures

(3) Evaluation of the target values

\subsubsection{Scheduling}

Scheduling deals with the allocation of new production orders, as shown in the upper part of Fig. 2. Input variables are information about the existing schedule of the production environment such as capacity units, capacity utilization situation and time allocation of already planned orders as well as data of the orders to be planned and cost parameters. Within the framework of scheduling, sequences of $5+1$ priority rules are selected on the basis of their influence on the target figure's minimum total delay time, average capacity utilization and minimization of economic losses. The considered priority rules are based on the individual time parameters of the work process (WP). The latest end time (LET) of an order corresponds to the delivery date at order level. The following formula is obtained for LET by mapping the time relationships:

$L E T=E S T+D+B T$

$E S T$ [-]: earliest start time, $D[\mathrm{~h}]$ : duration, $B T[\mathrm{~h}]$ : buffer time.

To consider the delivery date when prioritizing the operations, at least the three time parameters (LET, D and BT) of this equation must be taken into account. If the operations with the highest effort are preferred in scheduling, the following WP-specific priority rules result:

- Earliest LET

- Longest D

\section{- Lowest BT}

In addition to these three time criteria, the customer classes are also taken into account to give preference to the orders of the highest customer class when meeting delivery dates. A priority rule is used for the WP already planned to ensure minimum delay costs. However, no priority rule can be defined for the additional wage costs since they can only be taken into account during additional work hours planning. Thus, order-specific priority criteria based on logistical and economic objectives have been defined with this methodology:

- Already planned orders first

- Highest customer class

The corresponding schedule is created according to the priority rules. If several schedules are equivalent, they are evaluated systematically according to the further rules until one schedule remains. The order in which the priority rules are used is not initially determined. Therefore, 120 priority rule orders are created by complete permutation:

$P=n !=120$

for

$n=5$

$P[-]$ : number of different schedule scenarios, $n[-]$ : number of exchangeable priority rules.

If several orders are equivalent in all priority criteria of the five priority rules, the first in-first out (FIFO) rule is used instead. All resulting schedule alternatives are checked for possible delivery date deviations. If all schedules have deviations, they are managed in the optimization.

\subsubsection{Optimization}

Capacity adjustments are considered depending on the delivery date deviations. First is the allocation of additional working hours. These are released as required and the 120 sequences are recalculated. Additional work planning is carried out systematically according to the schedule to maintain minimum additional wage costs. For this purpose, the amount of hours necessary for completion on time are released from the additionally required work shifts. The planning based on the Gantt chart is carried out by activating additional capacity units that have already been blocked. All subsequent operations are postponed accordingly. For each planned additional hour, the units of all capacity units must be unlocked to maintain the assignment sequence of the WP starting with the earliest delivery date that is not met. 
If delivery date deviations exceed one operating day or one blocked working hour, the deviation is not eliminated. This remaining delay can only be minimized by planning further hours after the corresponding delivery date. In this case, the number of additional working hours corresponds to the number of unblocked capacity units between the delivery date and the current end of processing of the delayed order.

After allocation of additional working hours, all schedules are checked again for their adherence to delivery dates. The main objective of scheduling is to achieve the highest possible adherence to delivery dates according to customer classes. The priority rules cannot guarantee this requirement continuously due to the capacity and sequence conditions. Therefore, orders should be postponed in case of remaining delivery date deviations to minimize the delay of A- and subsequently B-class orders. Different shift scenarios result if there are several orders of lower classes available. These scenarios may have different degrees of fulfillment regarding the objective of optimization and are therefore all calculated and evaluated in a structured way. The number of possible shift scenarios can be calculated as a mathematical combination problem (combination without repetition):

$N=\sum_{k=1}^{m} k$

$N$ [-]: number of possible shift scenarios, $m[-]$ : number of postponable orders.

\subsubsection{Evaluation}

In all cases, several of the 120 schedules may produce a satisfactory result. This requires a suitable evaluation procedure to meet the target figure's minimum total delay time, average capacity utilization and minimization of economic losses. The evaluation of the scheduled scenarios is based on the logistic and economic objectives and is carried out by systematic filtering of schedules, as shown in Fig. 3. The filter criteria were selected as follows. To retain as many customers as possible, the ability to deliver has the highest priority. In this context, first possible deviations of the delivery date from new orders should be minimized and evenly distributed among all planned orders. The delay in the orders already planned is considered in the second step. Thus, delay costs can be kept at a minimum. Higher customer classes are preferred in both evaluation steps. High capacity utilization and short lead times are achieved to fulfill low process costs and short idle times. These two goals are supported by a constant capacity requirement.

\subsection{Cost model}

The bid price is determined individually for each incoming order. It can be calculated by Eq. 5 without the consideration of additional costs. The margin $M_{i}$ refers to the surcharge on the production cost price of the order and thus the common profit share in offer calculation. The amount of profit markup can be determined for each offered price individually according to customer, product and market situation. Within the scope of this work, it is set as constant for simplification.

$O_{P, i}=C_{m, i} \cdot\left(1+M_{i} / 100 \%\right)$

$O_{P, i}[€]$ : price of order $i, C_{m, i}[€]$ : production costs of order $i$, $M_{i}$ [\%]: margin of order $i$.

For this, the production costs $C_{m, i}$ of an order $i$ are defined as shown in Eq. 6-8. Thereby multiple machine operation is disregarded.

$C_{m, i}=M_{c, i}+P_{c, i}$

with

$M_{c, i}=M_{h r, i} \cdot t_{p, i}$

$P_{c, i}=L_{c, i}+R_{p o, i}$

$M_{c, i}[€]:$ machine costs of order $i, P_{c, i}[€]:$ personnel costs of order $i, M_{h r, i}[€ / \mathrm{h}]$ : machine hour rate for order $i, t_{p, i}[\mathrm{~h}]$ : time of production (process and set-up time) for order $i, L_{c, i}$

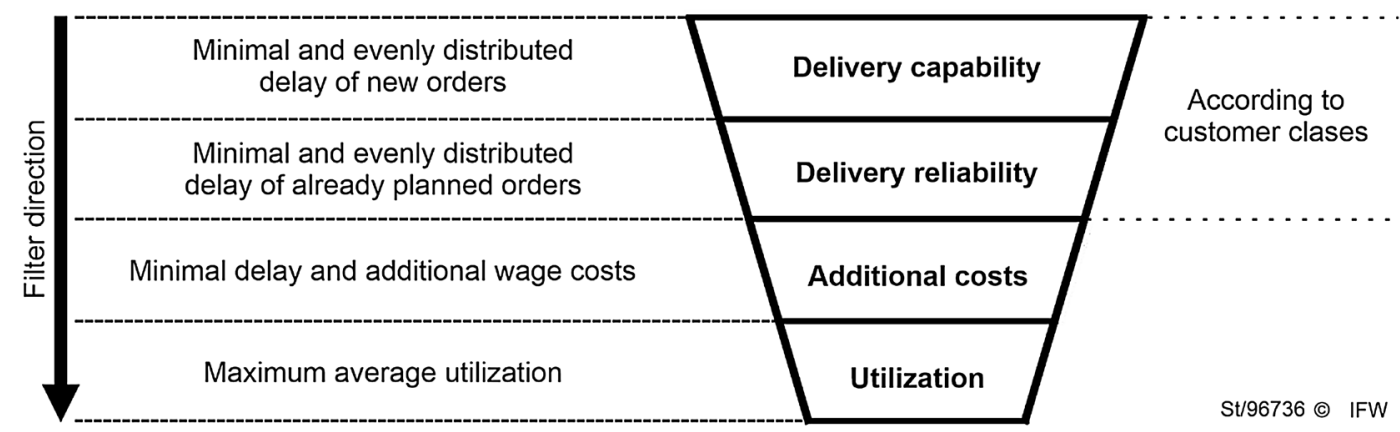

Fig. 3 Evaluation procedure of steps with more than one possible schedule 
$[€]$ : production labor costs for order $i, R_{p o, i}[€]$ : remaining production overheads of order $i$.

According to conventional calculation, the product costs is directly determined by applying the preceding formula through the use of a uniform machine hour and personnel cost rate. To link pricing to capacity utilization, the calculation of the machine hour rate and labor costs must linked to the different scheduling scenarios coming from schedule model. This results in the following dependencies:
Equation 12 guarantees that all additional costs are added to the order which caused them. Additional costs incurred on orders that have already been scheduled will be allocated evenly on to the new incoming orders.

\section{Use case setup}

The use case represents the production of a German SME and

$L_{c, i}=l_{c} \cdot\left(t_{\mathrm{p}, \text { normal }, i}+t_{\mathrm{p}, \text { late }, i} \cdot R_{\text {late }}+t_{\mathrm{p}, \text { night }, i} \cdot R_{\text {night }}+t_{p, \text { weekend }, i} \cdot \overline{R_{\text {weekend }}}\right)$

MTO supplier from the aerospace industry. The collected data

$L_{i}[€]$ : production labor costs for order $i, l_{c}[€ / \mathrm{h}]$ : production wage cost rate, $t_{\mathrm{p}, \text { normal }}[\mathrm{h}]$ : working hours on standard shift, $t_{\mathrm{p}, \text { late }}[\mathrm{h}]$ : working hours on late shift, $t_{\mathrm{p}, \text { night }}[\mathrm{h}]$ : work hours on night shift, $t_{p, \text { weekend }}[\mathrm{h}]$ : work hours on weekend, $R_{\text {late }}[-]$ : working hour rate factor for late shift, $R_{\text {night }}[-]$ : working hour rate factor for night shift, $R_{\text {weekend }}[-]$ : working hour rate factor for weekend.

$M_{h r, i}=M_{h r, i}^{v a r}+\frac{\left(\left(C W_{\text {end }}+1\right)-C W_{\text {start }}\right) \cdot M_{d p o}}{t_{e, p r e}+t_{p, i}+t_{e, p a s t}}$

$M_{h r, i}^{v a r}[€ / \mathrm{h}]$ : variable machine costs for order $i, C W_{\text {end }}[-]:$ calendar week at the end of production of order $i, C W_{\text {start }}[-]$ : calendar week at the start of production of order $i, M_{d p o}[€]$ : machine-dependent production overhead costs per planning period, $t_{e, p r e}[\mathrm{~h}]$ : sum of planned time of production of a machine till start of production of order $i, t_{e, p a s t}[\mathrm{~h}]$ : sum of planned time of production of a machine after introducing additional work hours to manufacture the order $i$.

The order-related delay costs must also be taken into account when calculating the planning scenario-specific price of an order. Therefore, additional work hours and the order-related delay costs are added as they occur. Accordingly, the new production costs are calculated as follows:

$C_{m, i}^{\text {new }}=C_{m, i}+C_{a, i}$

with

$C_{a, i}=\sum_{k=1}^{o} R_{\text {delay }, k} \cdot t_{\text {delay }, k} \cdot O_{p, k}$

$C_{m, i}^{\text {new }}[€]$ : new production cost price of order $i, C_{a, i}[€]$ : total additional costs due to order postponement caused by order $i$, o [-]: number of delayed orders, $R_{\text {delay, },}[1 / \mathrm{h}]$ : delay rate of order $k, t_{\text {delay }, k}[\mathrm{~h}]$ : time of delayed delivery of order $k, O_{p, k}$ $[€]$ : price of order $k$.

The following applies to the new offer price of an order:

$O_{P, i}^{n e w}=C_{m, i}^{n e w} \cdot\left(1+M_{i} / 100 \%\right)$

$O_{P, i}^{\text {new }}[€]$ : new offer price of order $i$. consists of three to nine already scheduled orders and 9 to 27 incoming orders, in three consecutive planning periods. The capacity contingents of the customer classes analyzed by the customer model and further processed to the ARIMA forecast. The order description consists of order number, customer class and work plan. The order work plan includes three to five work processes accessing three different capacity units, as seen in Fig. 4. The respective predecessors, relationships and the previous planned production time are considered. For cost calculating, the labor costs are based on the bargaining table of the labor union for metalwork. The cost factor to calculate the machine hour rates and the penalty charges for delayed deliveries are based on the general terms and conditions of the customer. The Algorithm and graphic user interface (GUI) implementation relies on $\mathrm{C \#}$ coding. The input parameters used are shown in Table 1.

A validation is carried out by checking the procedure of the algorithm and the suitability of the software application. The followed points are checked:

- Generate schedules by changing the priority order

\section{Existing production environment}

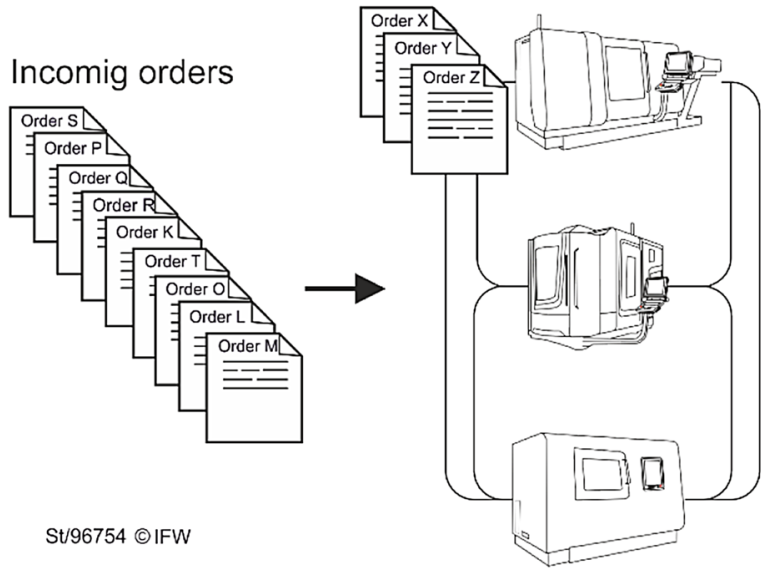

Fig. 4 Case study environment 
Table 1 Input parameters for experimental evaluation

\begin{tabular}{ll}
\hline Input parameter & Default value \\
\hline$R_{\text {po,i }}$ & $0.75 L_{c i}$ \\
$R_{\text {late }}$ & $25 \%$ \\
$R_{\text {night }}$ & $50 \%$ \\
$R_{\text {weekend }}$ & $75 \%$ \\
$M_{i}$ & $18 \%$ \\
$l_{c}$ & $17 € / \mathrm{h}$ \\
\hline
\end{tabular}

- Planning overtime

- Execute shift scenarios

- Calculate evaluation data

- Evaluate and filter flow charts

- Calculate offer prices

- Display planning results in GUI

\subsection{Use case evaluation}

The goal of the evaluation is to demonstrate the target achievement of minimizing A-class customers' delays. In addition, the functionality will be tested in practice against the use of one simple priority rule, as it has taken place so far in the industrial practice of the MTO supplier. To give an insight to the respective behavior of the algorithm, the evaluation on 12 orders in one planning period is discussed. As shown in Fig. 5, the presented approach decreases the delay of A-class customer orders significantly, while maintaining lower total costs despite the additional costs. The use of customer class-dependent priority rules achieves a decrease of up to $67 \%$ for A-class and $36 \%$ for B-class customers, but at the disadvantage of C-class customer orders. In total, lead times (41\%), delays (41\%) and costs (5\%) are reduced (cf. Fig. 6).

By taking additional work hours and the buffer times of each order into account, all order delays are reduced by $80 \%$.

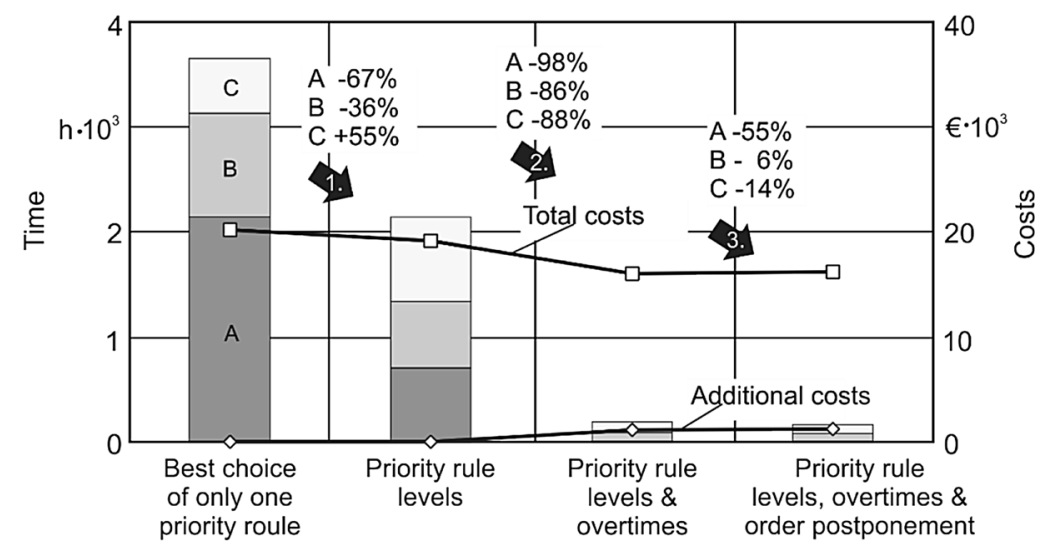

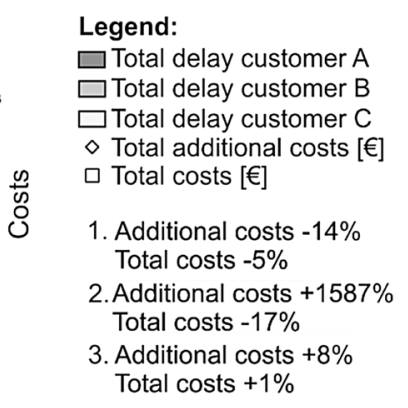

St/96755 ㅇIFW

Fig. 5 Customer class dependent delay and cost development
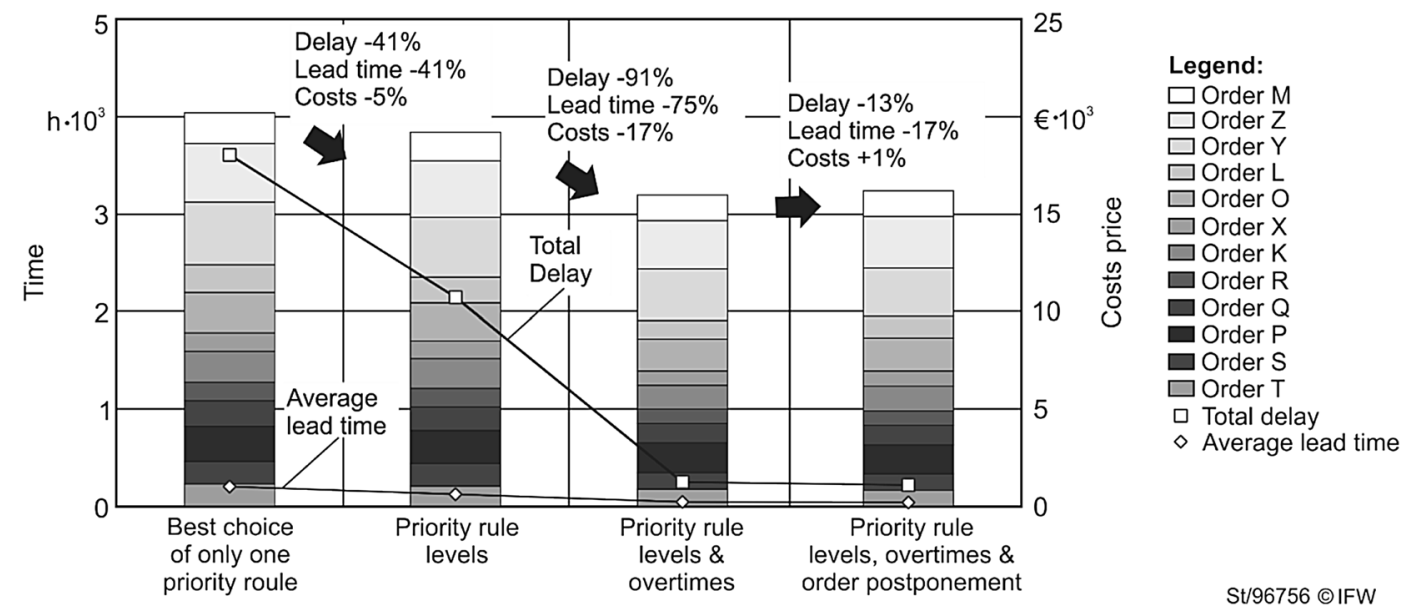

Fig. 6 Results of cost price changes 
At the same time, additional costs increase due to the use of overtime hours. However, the total costs decrease by another $17 \%$. The reason for this is the machine hour rate, which depends on capacity utilization and therefore counteracts the additional wage costs.

The use of order postponement as the last step in the scheduling module implies a second decrease in additional costs, which in this case is also a decrease in total costs by $1 \%$ (cf. Fig. 6). The average lead time and total delay are again significantly reduced by at least $13 \%$. This ensures a good balance between the customer requirements and at the same time the economic goals of the manufacturer.

By apportioning the cost to the caused orders, a profit maximization in this environment of up to $23 \%$ could be achieved, as shown in Table 2.

The presented approach has different effects on enterprises' key performance indicators. Depending on which indicator is recorded, the three optimization methods of the scheduling module are better suited in combination. Using the shown adjustment measures in combination has a positive effect on the lead time, the sum of delays and the profit maximization, as shown in Table 2 and Fig. 6. Scheduling without using order postponement, on the other hand, affects the level of total costs. For enterprises that only consider the additional wage costs or where very high additional wage costs are to be expected, sufficient planning can already be carried out with the proposed priority-based scheduling. The fulfilment of objectives can only be achieved in combination with established adaptation measures and the selected priority levels. A separate use does not lead to a sufficient target realization. Table 2 shows that even the best fitting priority rule does not reach the optimization potential of the new approach. Although the "Earliest LET" priority rule was applied most frequently, the other rules were also used regularly and achieved good results. A general exclusion from certain priority rules is therefore not possible and a prediction of the required priority sequence for defined planning steps cannot be made.

\subsection{Discussion}

The evaluation is conducted for several order combinations, as mentioned in Sect. 4. Thus, the algorithm shows stable behavior for varying amounts of orders within an equal distribution of customer classes. The basic findings remain the same, only the computing time increases. Regarding the industrial feasibility of the presented approach, the following simplifying assumptions must be considered. A possible rejection of the higher bid price by the customer was not taken into account. A consideration of rejections in the study would fluctuate the number of new orders. It can be assumed that the scheduling algorithm is not affected. Furthermore, the modelling of customer decisions in acceptance or rejection of bid prices was not subject to the project and requires further analysis. In addition, the transfer of additional costs to the bid price can lead to prices, which may not be competitive. In order to avoid this risk, a profit maximization limit could be set depending on the level of the cost price. If this limit is exceeded, a share of the additional costs must be covered by the company. Alternatively, this share could also be allocated to orders whose profit maximization limit has not yet been reached.

The forecast of capacity contingents on the basis of historical data is subject to a certain degree of uncertainty, which is not considered in this approach. Thus, this approach requires the implementation of a factor to take into account the probability of a wrong or imprecise forecast.

\section{Conclusion and outlook}

Due to the increasing individualization of products and fluctuations in demand, the task of production scheduling requires a particularly high level of effort in MTO production. Thus, it offers a high degree of optimization. Despite the risk of economic losses, there is a lack of approaches that are able to control fluctuations in demand and provide planning results to meet economic targets.

Table 2 Study results

\begin{tabular}{lrrrr}
\hline & $\begin{array}{l}\text { Best choice of only one } \\
\text { priority rule }\end{array}$ & Priority rule levels & $\begin{array}{l}\text { Priority rule levels and } \\
\text { overtime }\end{array}$ & $\begin{array}{l}\text { Priority rule levels, over- } \\
\text { time and order postpone- } \\
\text { ment }\end{array}$ \\
\hline Total costs $[€]$ & $20,187.04$ & $19,186.16$ & $16,001.56$ & $16,170.40$ \\
Total delay cost $[€]$ & 83.87 & 71.98 & 7.62 & 9.56 \\
Add. wage costs $[€]$ & 0.00 & 0.00 & $1,207.00$ & $1,300.50$ \\
Total add. costs [€] & 83.87 & 71.98 & $1,214.62$ & $1,310.06$ \\
$\begin{array}{l}\text { Profit maximization through add. } \\
\text { costs apportionment [\%] }\end{array}$ & 3.25 & 3.17 & 22.17 & 23.57 \\
\hline
\end{tabular}


Within the scope of this work, a software-supported solution was developed with the aim of achieving the highest possible delivery capability and link capacity adjustment measures with bid pricing. The evaluation and thus the selection of the suitable schedule takes place according to the set target values. Additional work hours can be planned according to the capacity requirements. It is also possible to postpone low-level orders (C-class customers) to achieve a higher delivery reliability for the highest customer class. A pricing mechanism was developed for quotation calculation, which takes into account the costs for capacity utilization and capacity adjustments measures.

The application study of the algorithm showed that the minimization of possible schedule variances while maintaining high capacity utilization is fulfilled by the combination of all measures at the latest. Systematic additional work hours planning ensures minimum additional costs. For the application case, all order delays could be reduced by up to $95 \%$ and total costs by $21 \%$ compared to using the most appropriate priority rule. This emphasizes the need of taking into account costs in scheduling in an early stage of the process of bid pricing.

Splitting the problem into individual modules reduces the complexity of the mathematical problem, but requires a higher degree of organization between the modules. Therefore, it is necessary to determine defined standardized interfaces for an industrial application of the entire method, as described in Sect. 3.

Up to now, the evaluation has only been performed on real data of an MTO supplier regarding a defined planning period, which probably does not contain all possible order combinations. For a more detailed analysis of the presented method, further research in a simulation study including robustness tests are necessary. In addition, a more detailed investigation of the bidding process is necessary to estimate to what extent a rejection of higher bid prices by the customer takes place.

Acknowledgement Open Access funding provided by Projekt DEAL. The authors thank the Federal Ministry of Education and Research of Germany (BMBF) for its financial and organizational support of the project "Dynamic capacity planning and control in manufacturing SME" (project "KaPro", 02P15K563).

Open Access This article is licensed under a Creative Commons Attribution 4.0 International License, which permits use, sharing, adaptation, distribution and reproduction in any medium or format, as long as you give appropriate credit to the original author(s) and the source, provide a link to the Creative Commons licence, and indicate if changes were made. The images or other third party material in this article are included in the article's Creative Commons licence, unless indicated otherwise in a credit line to the material. If material is not included in the article's Creative Commons licence and your intended use is not permitted by statutory regulation or exceeds the permitted use, you will need to obtain permission directly from the copyright holder. To view a copy of this licence, visit http://creativecommons.org/licenses/by/4.0/.

\section{References}

1. Denkena B, Dittrich MA, Winter F (2017) Adaptive process planning and control. In: Denkena B, Mörke T (eds) Cyberphysical and gentelligent systems in manufacturing and life cycle. Academic Press, London, pp 281-293

2. Duffie N, Chehade A, Athavale A (2014) Control theoretical modeling of transient behaviour of PPC: a review. Procedia CIRP 17:20-25. https://doi.org/10.1016/j.procir.2014.01.099

3. Slotnick SA (2011) Order acceptance and scheduling: a taxonomy and review. Eur J Oper Res 212:1-11. https://doi. org/10.1016/j.ejor.2010.09.042

4. Chehade A, Duffie N (2014) Optimal dynamic behavior of adaptive WIP regulation with multiple modes of capacity adjustment. Procedia CIRP 19:168-173. https://doi.org/10.1016/j. procir.2014.05.002

5. Charnsirisakskul K, Griffin PM, Keskinocak P (2006) Pricing and scheduling decisions with lead-time flexibility. Eur J Oper Res 171:153-169. https://doi.org/10.1016/j.ejor.2004.07.062

6. Pourbabai B (1989) A short term production planning and scheduling model. Eng Costs Prod Econ 18:159-167. https:// doi.org/10.1016/0167-188X(89)90034-7

7. Pourbabai B (1992) Optimal selection of orders in a just-in-time manufacturing environment: a loading model for a computer integrated manufacturing system. Int J Comput Integr Manuf 5(1):38-44. https://doi.org/10.1080/095119X9208547564

8. Carvalho AN, Oliveira F, Scavarda LF (2015) Tactical capacity planning in a real-world ETO industry case: an action research. Int J Prod Econ 167:187-203. https://doi.org/10.1016/j. ijpe.2015.05.032

9. Alfieri A, Tolio T, Urgo M (2011) A project schedule approach to production planning with feeding precedence relations. Int $\mathrm{J}$ Prod Res 49(4):995-1020. https://doi.org/10.1080/0020754100 3604844

10. Alfieri A, Tolio T, Urgo M (2016) A two stage stochastic programming project schedule approach to production panning. Int J Adv Manuf Technol 62(1-4):279-290. https://doi. org/10.1007/s00170-011-3794-4

11. Ho JW, Fang CC (2013) Production capacity planning for multiple products under uncertain demand conditions. Int J Prod Econ 141:593-604. https://doi.org/10.1016/j.ijpe.2012.09.016

12. Thürer M, Stevenson M, Silva C (2011) Three decades of workload control research: a systematic review of the literature. Int J Prod Res 49(23):6905-6935. https://doi.org/10.1080/00207 543.2010 .519000

13. Kingsman B (2000) Modelling input-output workload control for dynamic capacity planning in production planning systems. Int J Prod Econ 68(1):73-93. https://doi.org/10.1016/S0925 $-5273(00) 00037-2$

14. Kingsman B, Hendry L, Mercer A, Souza A (1996) Responding to customer enquiries in make-to-order companies problems and solutions. Int J Prod Econ 46-47:219-231. https://doi. org/10.1016/0925-5273(95)00199-9

15. Ceryan O, Koren Y (2009) Manufacturing capacity planning strategies. CIRP Ann Manuf Technol 58:403-406. https://doi. org/10.1016/j.cirp.2009.03.034

16. Santana A, Afonso P, Zanin A, Wernke R (2017) Costing models for capacity optimization in Industry 4.0: trade-off between used capacity and operational efficiency. Procedia Manuf 13:1183-1190. https://doi.org/10.1016/j.promfg.2017.09.193

17. Wouters M, Stecher J (2018) Development of real-time product cost measurement: a case study in a medium-sized manufacturing company. Int J Prod Econ 183(1):235-244. https://doi. org/10.1016/j.ijpe.2016.10.018 
18. Ou J, Feng J (2019) Production lot-sizing with dynamic capacity adjustment. Eur J Oper Res 272:261-269. https://doi. org/10.1016/j.ejor.2018.06.030

19. Renna P (2015) Dynamic pricing of excess capacity in production networks by fuzzy logic. Int J Comput Integr Manuf 29(6):611-621

20. Talluri KT, Ryzin GJ van, Karaesmen IZ, Vulcano GJ (2008) Revenue management: models and methods. Proceedings of 2008 Winter Simulation Conference, pp145-156. 10.1109/ WSC.2008.4736064

21. Rehkopf S (2006) Revenue Management-Konzepte zur Auftragsannahme bei kundenindividueller Produktion. Dissertation, Technische Universität Braunschweig
22. Denkena B, Dittrich MA, Stamm S (2018) Dynamic bid pricing for an optimized resource utilization in small and medium sized enterprises. Procedia CIRP 67:516-521. https://doi.org/10.1016/j. procir.2017.12.254

Publisher's Note Springer Nature remains neutral with regard to jurisdictional claims in published maps and institutional affiliations. 